\title{
Recent Advances in Anti-Aging
} Medicine

\author{
Da-Hye Son ${ }^{1}$, Woo-Jin Park'2, Yong-Jae Lee ${ }^{1, *}$ \\ 'Department of Family Medicine, Yonsei University College of Medicine, Seoul, Korea \\ ${ }^{2}$ Department of Internal Medicine, Incheon St. Mary's Hospital, College of Medicine, The Catholic University of Korea, Incheon, Korea
}

A rapidly aging population in Korea has led to increased attention in the field of anti-aging medicine. The purpose of anti-aging medicine is to slow, stop, or reverse the aging process and its associated effects, such as disability and frailty. Anti-aging medicine is emerging as a growing industry, but many supplements or protocols are available that do not have scientific evidence to support their claims. In this review, the mechanisms of action and the clinical implications of anti-aging interventions were examined and explained. Calorie restriction mimetics define compounds that imitate the outcome of calorie restriction, including an activator of AMP protein kinase (metfor$\mathrm{min}$ ), inhibitor of growth hormone/insulin-like growth factor-1 axis (pegvisomant), inhibitor of mammalian target of rapamycin (rapamycin), and activator of the sirtuin pathway (resveratrol). Hormonal replacement has also been widely used in the elderly population to improve their quality of life. Manipulating healthy gut microbiota through prebiotic/probiotics or fecal microbiota transplantation has significant potential in anti-aging medicine. Vitamin D is expected to be a primary anti-aging medicine in the near future due to its numerous positive effects in the elderly population.

Keywords: Aging; Hormone Replacement Therapy; Calorie Restriction; Vitamin D

Received: July 22, 2019, Revised: September 11, 2019, Accepted: September 16, 2019

${ }^{*}$ Corresponding Author: Yong-Jae Lee https://orcid.org/0000-0002-6697-476X

Tel: +82-2-2019-2630, Fax: +82-2-3462-8209, E-mail: ukyjhome@yuhs.ac 


\section{INTRODUCTION}

An increasing population age, defined as a rising median age in the population, has emerged as one of the most significant challenges and financial burdens for many countries. The Korean population is rapidly aging and becoming an aged society, as are other developed countries. As the population of Korea is rapidly aging due to low fertility and a long life span, the problem of the elderly is becoming a social issue. Approximately $14.3 \%$ of the Korean population was aged 65 or older in 2018, and the percentage is expected to rapidly rise to $20.3 \%$ in 2027 and $34.4 \%$ in $2050 .{ }^{1)}$ Recent advances in science and medicine have led to research that elucidates aging mechanisms, and anti-aging medicine is emerging as a growing industry. The definition of anti-aging medicine is as follows: "measures taken to slow, stop, or even reverse phenomena related to aging, as well as to increase life span." Anti-aging related health supplements, cosmetics, and hormone replacement therapy (HRT) have been developed and advertised in the media, but there is still a lack of scientific evidence. In this article, we will review the behavioral, dietary, and pharmacological approaches of anti-aging medicine.

\section{CALORIE RESTRICTION AND MIMETICS}

Among all the anti-aging interventions, dietary interventions have shown the greatest potential. Calorie restriction, without malnourishing the individual, slows the aging process and expands the average and maximal lifespan in animals of diverse origin., ${ }^{3,4)}$ McCay et al. ${ }^{5)}$ reported that restricting food intake in rats extended the median and maximum life span and decreased the onset and severity of chronic diseases. Subsequent findings emphasized that calorie restriction has effects on life-span in a wide range of organisms. ${ }^{4,6,7)}$ The positive effects of calorie restriction in humans has also been demonstrated in many studies. Calorie restriction while maintaining adequate nutrition has beneficial effects such as protecting against the development of obesity, cardiovascular disease, hypertension, and cancer. ${ }^{8)}$ In a controlled study, calorie restriction with high levels of physical activity showed a decrease in blood pressure, body weight, serum cholesterol levels, insulin levels, and other anthropometric and physiological parameters. ${ }^{9)}$ The mechanisms by which calorie restriction induces lifeextending properties are not fully understood, but the following four potential target pathways have been suggested: the activation of AMP protein kinase (AMPK) ${ }^{10)}$ and sirtuins, ${ }^{11)}$ inhibition of insulin-like growth factor-1 (IGF-1) signaling, ${ }^{12)}$ and inhibition of mammalian target of rapamycin (mTOR) by rapamycin. ${ }^{13)}$ These pathways are the main hypothesized mechanisms of action of calorie restriction that control cell growth, mitochondrial function, and autophagy directly or indirectly. ${ }^{14)}$ However, despite the proven benefits of calorie restriction, it is a difficult technique to successfully use in humans as it is challenging to apply the treatment long-term, since it requires a high level of determination and self-control. This paradox led to the discovery of compounds that imitate the outcome of calorie restriction on health and lifespan without an actual restriction in calorie intake. ${ }^{15)}$ These compounds were named 'calorie restriction mimetics' (CRM). Figure 1 illustrates the schematic mechanisms in relation to CRM.

\section{Activator of AMP Protein Kinase}

AMPK is activated when cellular energy levels are low, resulting in increased levels of AMP. ${ }^{16)}$ Activation of AMPK regulates whole-body

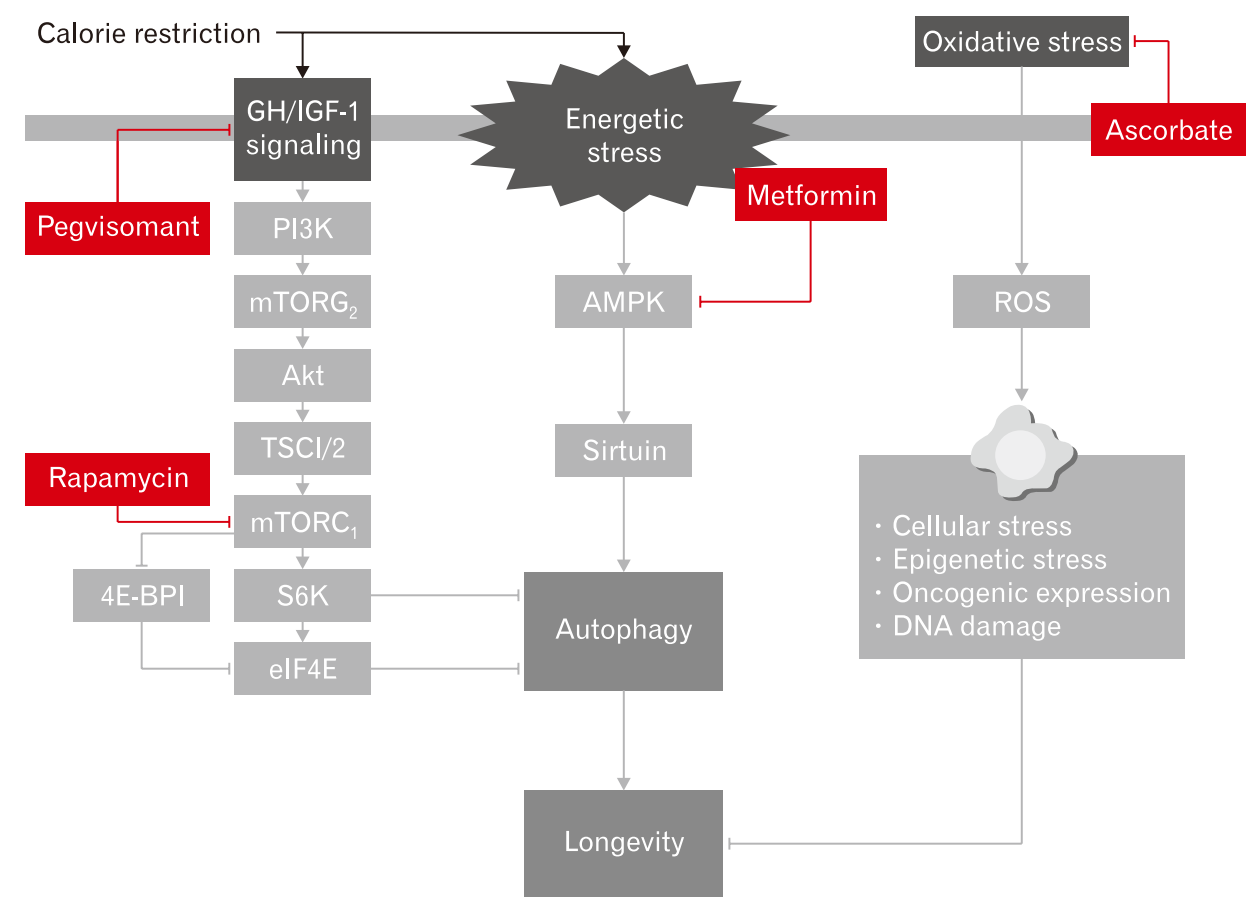

Figure 1. Schematic view of the interrelationship between calorie restriction mimetics and oxidative stress and their clinical implications on longevity. GH, growth hormone; IGF-1, insulin-like growth factor-1; PI3K, phosphoinositide 3-kinase; mTOR, mammalian target of rapamycin; TSC, tuberous sclerosis complex; S6K, S6 kinase; elF4E, eukaryotic initiation factor 4E; 4E-BP1, 4E binding protein 1 ; ROS, reactive oxygen species. 
metabolism. Activation of AMPK resulted in insulin-sensitizing effects along with the increased absorption of glucose in skeletal muscles, reduced hepatic glucose production, and increased fatty acid oxidation in several tissues. ${ }^{16)}$ Metformin, the first-line drug for type 2 diabetes mellitus (T2DM), inhibits gluconeogenesis with the activation of AMPK in the liver. ${ }^{17)}$ Numerous studies have demonstrated that metformin has positive effects on the anti-aging process among patients with T2DM. ${ }^{18)}$ In the UK Prospective Diabetes Study, metformin decreased the risk of cardiovascular disease, ${ }^{19)}$ cancer incidence, and allcause mortality. ${ }^{20)}$ when compared to other anti-diabetic drugs. ${ }^{21)}$ Furthermore, a large retrospective observational study that included over 180,000 individuals reported that patients with T2DM treated with metformin monotherapy lived longer than non-diabetic controls, but they did not investigate for a dose-response association. ${ }^{18)}$

\section{Inhibitors of Growth Hormone/Insulin-Like Growth Factor-1 Axis}

Recent studies have shown that reduced somatotropic activity is related to an inhibited rate of aging, delayed onset of age-related diseases, and frailty associated with an extended lifespan. ${ }^{22)}$ IGF-1 is secreted by the liver in response to growth hormone (GH). Although a deficient level of IGF-1 is lethal, several studies have reported that a reduction in IGF-1 levels or IGF-1 action has positive effects on protecting against cancer, diabetes mellitus, and can extend the lifespan of animal models. ${ }^{23)}$ Similar results have been shown in GH receptor-deficient Laron syndrome patients. Cells/tissues that produce or respond to GH and/ or IGF-1 can be pharmacological targets for lowering IGF-1 action. One of the somatostatin analogs decreases serum GH/IGF-1 levels by suppressing GH secretion by pituitary somatotrophs. Regrettably, these compounds also suppress insulin secretion and have significant adverse effects including diarrhea, anorexia, the formation of gallstones. Thus, the use of somatostatin analogs as an anti-aging treatment is currently unwarranted. Pegvisomant, another drug for treating acromegaly, is the GH receptor antagonist. It inhibits GH action by binding to and blocking the GH receptor. ${ }^{24)}$ Pegvisomant has positive effects on both longevity and healthy aging by increasing insulin sensitivity and lowering the IGF-1 level. Regarding adverse effects, Trainer et al. ${ }^{24)}$ reported that liver enzymes were elevated in a few patients.

\section{Inhibitors of Mammalian Target of Rapamycin}

The mTOR pathway is another nutrient sensing pathway which induces the lifespan extension effect of calorie restriction. The mTOR is a serine/threonine protein kinase that is part of the phosphoinositide 3-kinase-related kinase family and is found in two protein complexes including mTORC1 and mTORC2 with distinct protein components and substrates. ${ }^{25)}$ The mTORC1 controls protein translation, autophagy, and various cellular processes through the phosphorylation of substrates such as S6 kinase, 4E binding protein 1, and uncoordinated 51like kinase 1 . In the presence of sufficient nutrients, mTOR turns off stress resistance and autophagy, and subsequently activates translation. ${ }^{26)}$ Reduced mTOR signaling through genetic or pharmacological interventions generated lifespan extension in various species and studies are currently being conducted in primates and humans. ${ }^{27}$

Rapamycin is a macrolide and is used as a potent immunosuppressant drug. It is the main antagonist of mTOR signaling. National Institute on Aging Interventions Testing Programs first reported in 2009 that rapamycin extends the lifespan of wild-type mice. Since then, numerous studies have confirmed the strong positive effect of rapamycin on life span. ${ }^{28)}$ However, rapamycin has significant adverse effects, including metabolic dysregulation (e.g., hyperglycemia, hyperinsulinemia, and insulin resistance) and proliferative defects in hematopoietic lineages. ${ }^{29)}$ These severe side effects limit its consideration and clinical use as an anti-aging drug. Safety studies using rapamycin in healthy individuals are required in the future.

\section{Activators of the Sirtuin Pathway}

NAD+ dependent deacetylases known as sirtuins (SIRT 1 to 7) modulate the activity of proteins that are related to energy metabolism, stress resistance, cell survival, and longevity. ${ }^{30)}$ Sirtuins are homologous to yeast silent information regulators (sir2). Overexpression of sir2 extended the lifespan of yeast, drosophila, and Caenorhabditis elegans. ${ }^{31)}$ Although the mechanism by which sirtuins induce anti-aging effects has not been fully elucidated, some studies have shown that sirtuins promote lifespan by stimulating autophagy. Furthermore, there are reports of sirtuins mediating antioxidant defense, improving mitochondrial function, and lowering the serum IGF-1 level. ${ }^{32)}$ Thus, sirtuin activating compounds have become a target for many anti-aging studies. Naturally occurring phytochemicals including, quercetin, myricetin, piceatannol, and polyphenols (resveratrol) are known as SIRT-1 agonists. ${ }^{33)}$ The effect of resveratrol on improving health and lifespan have been reported in yeast, drosophila, and nematodes. ${ }^{31,34)}$ In other animal models, resveratrol has failed to promote lifespan, but many health benefits have been confirmed. ${ }^{14)}$ Resveratrol improved motor performance, bone health, and reduced cardiac failure, seizures, Parkinson's disease, and Alzheimer's disease. ${ }^{35-40)}$ Resveratrol is also reported to improve memory performance in the elderly and regulate glucose and lipid levels in adults with T2DM and obesity. ${ }^{41,42)}$

\section{HORMONAL REPLACEMENT}

Hormone levels decrease with age, and this process is related to decreased secretion from the pituitary gland, adrenals, and gonads. ${ }^{43)}$ Decreased hormone levels are associated with decreases in bone mineral density (BMD), muscle mass, sexual desire, erectile function, and intellectual activity. In this context, hormone supplements have been widely used to help reverse the effects of aging and improve the quality of life in the elderly.

\section{Estrogen and Progestins}

Two-thirds of women suffer from uncomfortable symptoms like hot flashes or vaginal dryness during perimenopause, and HRT is used to reduce such symptoms. Estrogens alone, or together with progester- 
one, have positive effects on osteoporosis treatment and have been used to prevent vertebral and non-vertebral fractures. However, a Women's Health Initiative (WHI) study reported a higher risk for cardiovascular disease, thromboembolic event, stroke, and breast cancer with a combined treatment of estrogens and progestin. ${ }^{44)}$ Following the results of the WHI study, new guidelines recommended hormone supplements with lower dose for the shortest amount of time. The Food and Drug Administration in the United States suggests using HRT only for hot flashes and vaginal dryness. ${ }^{45}$ HRT can also be used for the prevention of osteoporosis when other treatments are not available. $^{45)}$

\section{Testosterone}

Low testosterone levels in older men has been associated with various age-associated conditions. ${ }^{46,47)}$ Sarcopenia and osteoporosis are more frequent in older men with low plasma testosterone levels. ${ }^{48,49)}$ Furthermore, several studies have demonstrated a relationship between low testosterone levels and mild cognitive impairment and Alzheimer's disease. ${ }^{50)}$ Thus, testosterone replacement therapy is beneficial as it can increase muscle mass, strength, and BMD in elderly men. ${ }^{51)}$ Cognitive function, including verbal, spatial, working memory, and visuospatial function, was improved by testosterone supplementation in elderly men. ${ }^{45)}$ One of the adverse effects of testosterone administration is polycythemia. For this reason, patients undergoing testosterone replacement therapy should have their hemoglobin or hematocrit levels checked every 6 months for a total duration of 18 months. Another main concern with testosterone replacement therapy is the potential risk of aggravating prostate cancer. Animal studies have reported that prostate cancer growth was stimulated by testosterone administration. ${ }^{52)}$ Thus, although recent studies have failed to confirm a relationship between testosterone levels and the risk of prostate cancer, testosterone replacement therapy should be seriously reconsidered in patients with active prostate cancer. ${ }^{53,54)}$ In general, the absolute contraindications of testosterone replacement therapy are as follows: suspected prostate cancer, severe symptoms of the lower urinary tract such as an International Prostate Symptom Score $>19$, hematocrit $>50 \%$, ischemic heart disease in the preceding 6 months, poorly controlled congestive heart failure, and untreated sleep apnea. ${ }^{45}$

\section{Dehydroepiandrosterone}

The dehydroepiandrosterone (DHEA) and its metabolite DHEA-sulfate are precursors for sex hormones produced by the adrenal gland, which are subsequently transformed into androgen or estrogen in the target tissue. ${ }^{45)}$ The decline of plasma DHEA levels with age is clinically associated with various age-related conditions. ${ }^{55)}$ Since ovarian production of estrogen decreases in postmenopausal women, the adrenal gland is the only source of estrogen through the peripheral conversion of DHEA. ${ }^{56)}$ In previous studies, DHEA supplementation was positively associated with muscle mass, muscle strength, physical performance, and BMD in both men and women. ${ }^{57-60)}$ Furthermore, DHEA administration has demonstrated beneficial effects on mood and sexual func- tion. ${ }^{61,62)}$ However, the relationship between DHEA and cognitive function has not been sufficiently researched. ${ }^{45)}$ Recent studies reported that low DHEA levels are related to a higher risk for atherosclerosis, heart failure, cardiovascular complications, and overall mortality. ${ }^{63)}$ Nevertheless, the relationship between DHEA and cardiovascular disease risk factors is still controversial. The adverse effects of DHEA are minimal, such as mild acne, seborrhea, facial hair growth, and ankle swelling in women. ${ }^{64,65)}$ There was no significant effect on hormonedependent tumors such as breast and prostate cancer, ${ }^{56,66)}$ but longer and larger studies are warranted to sufficiently prove the safety of DHEA. DHEA is not allowed in the Republic of Korea even though it is one of the most widely used anti-aging hormones in the United States.

\section{GUT MICROBIOTA}

\section{Gut Microbiota}

In recent years, the significant role of microbiota in regulating health status and lifespan has been demonstrated. ${ }^{2)}$ Microorganisms have been shown to affect many essential physiological and metabolic functions of host organisms and contribute to the maturation of immune function during early development. ${ }^{67)}$ Healthy gut microbiota plays a vital role in resistance to infection, inflammation, autoimmune and cancer prevention, and the regulation of the brain-gut axis. ${ }^{68)} \mathrm{Re}$ cently, many studies have reported evidence that microbiome-targeted interventions can have a therapeutic potential not only for age-associated diseases, but also for slowing down the aging process and for promoting longevity. In the gut of individuals living for over 100 years (centenarians), the Firmicutes population was rearranged and Proteobacteria was enriched. ${ }^{69)}$ The remodeling of the centenarians' microbiota is also characterized by a substantial decrease in Faecalibacterium prausnitzii and its relatives, which are symbiotics species with pronounced anti-inflammatory activity. Eubacterium limosum and its relatives, which are signature bacteria of a long life span, were higher in centenarians. ${ }^{69)}$ Another centenarian study reported that genes involved in short-chain fatty acid synthesis and the saccharolytic potential are decreased, while proteolytic functions of the intestinal metagenome were increased in elderly people compared to younger adults. ${ }^{70)}$ However, microbiota composition can be profoundly influenced by several confounding factors including diet, prebiotics, level of physical activity, drug use, and exposure to psychological stressors. Therefore, any interpretation of the results should take these confounding variables into account.

\section{Fecal Microbiota Transplantation}

Microbiota-targeted interventions include prebiotics and probiotics, particularly those containing Bifidobacterium and Lactobacillus. ${ }^{71,72)}$ The probiotic Lactobacillus rhamnosus GG ATCC 53103 has been shown to promote the anti-inflammatory pathways of resident microorganisms. ${ }^{73)}$ Fecal microbiota transplantation (FMT) is a radical management program that is used to restore the intestinal ecosystem through the transferring of liquid filtrate feces from a healthy donor 
Table 1. Types of anti-aging intervention

\begin{tabular}{ll}
\hline \multicolumn{1}{c}{ Category according to mechanism } & \multicolumn{1}{c}{ Drug or supplement } \\
\hline Calorie restriction mimetics & Metformin \\
Activation of AMP protein kinase & Pegvisomant \\
Inhibition of growth hormone/insulin like growth factor-1 axis & Rapamycin \\
Inhibition of mammalian target of rapamycin & Resveratrol \\
Activation of the sirtuin pathway & Estrogen and progestin, testosterone, and dehydroepiandrosterone \\
Hormonal replacement & Probiotics, prebiotics, fecal microbiota transplantation \\
Gut microbiota & Vitamin D 400 to 2,000 IU/d with sunlight exposure and foods \\
Vitamin D & \\
\hline
\end{tabular}

into the recipient's gastrointestinal tract. ${ }^{74)}$ FMT has been used as a therapeutic option for Clostridium difficile infection. ${ }^{75)}$ More recently, however, its potential benefit and safety have been demonstrated in non-gastrointestinal diseases, including those commonly associated with aging, T2DM, metabolic syndrome, atherosclerosis, and neurodegenerative diseases. ${ }^{68,76)}$ Despite the great therapeutic potential of the FMT procedure, its implementation in clinical practice is limited by several concerns. These concerns include problems with donor screening, the limited viability of fresh stool samples, fears about potential pathogen transmission, lack of a standardized treatment regimen, and patients not consenting to be treated. ${ }^{76)}$

\section{VITAMIN D}

Vitamin D is a significant pro-hormone for optimal intestinal calcium absorption for the mineralization of bone. ${ }^{77)}$ Recently, many studies have revealed numerous positive effects of vitamin D use in the elderly population. Vitamin D deficiency in the elderly is associated with decreased cognitive function, a higher risk of Alzheimer's disease, ${ }^{78)}$ loss of muscle mass and function, ${ }^{79)}$ and osteoporosis. Cross-sectional studies have demonstrated that a low level of vitamin $\mathrm{D}$ is related to a higher risk of cardiovascular diseases such as hypertension, heart failure, and ischemic heart disease ${ }^{80,81)}$ However, the effects of vitamin D as a supplement are still controversial. One study demonstrated that a high serum vitamin D concentration is associated with high atherosclerosis cardiovascular disease risk scores. ${ }^{82)}$

Since vitamin D production is usually stimulated by adequate sun exposure, vitamin D levels tend to be lower in elderly people with reduced outside activity. Vitamin D therapy in the elderly was shown to improve muscle mass and performance, and to a reduced the rate of falls. ${ }^{79)}$ Furthermore, a recent study reported that vitamin D also has an anti-cancer effect by inhibiting cancer cell growth in several types of cancer. ${ }^{83)}$ In this regard, numerous agencies and scientific organizations have developed recommendations for vitamin $\mathrm{D}$ therapy and also provide guidance on optimal serum 25-hydroxyvitamin D $(25[\mathrm{OH}] \mathrm{D})$ concentrations. The general target for the $25(\mathrm{OH}) \mathrm{D}$ concentration is above $30 \mathrm{ng} / \mathrm{mL}$, and the replacement dose can vary, ranging from between 400 and 2,000 IU/d depending on age, body weight, disease status, and ethnicity. ${ }^{84)}$ Vitamin D intake through natural food sources such as milk, beverages made from soy, almonds, and coconuts is also important in elderly people with low vitamin D levels. ${ }^{84)}$

\section{CONCLUSION}

Anti-aging medicine is a growing field in locations with an aging population, particularly in developed countries. Available anti-aging interventions are categorized in Table 1 according to their mechanisms of action. CRM define compounds that imitate the outcome of calorie restriction, and these include the activator of AMPK (metformin), inhibitor of GH/IGF-1 axis (pegvisomant), inhibitor of mTOR (rapamycin), and activator of the sirtuin pathway (resveratrol). Hormonal replacement such as estrogen, progestin, testosterone, and DHEA in the elderly have been widely used to improve various symptoms associated with frailty, body composition, cardiometabolic diseases, neurodegenerative diseases, and quality of life. Since HRT can increase the risk of thromboembolism or some types of cancer, it should be used with precautions. The composition of healthy gut microbiota through prebiotic/probiotics and FMT has a great potential for anti-aging medicine. Furthermore, vitamin D is expected to be a main anti-aging medicine in the near future due to its numerous positive effects in elderly population.

\section{CONFLICT OF INTEREST}

No potential conflict of interest relevant to this article was reported.

\section{ORCID}

Da-Hye Son: https://orcid.org/0000-0001-7464-996X

Woo-Jin Park: https://orcid.org/0000-0002-6679-8524

Yong-Jae Lee: https://orcid.org/0000-0002-6697-476X

\section{REFERENCES}

1. Statistics Korea. South Korea population and housing census 2018 [Internet]. Daejeon: Statistics Korea; 2018 [cited 2019 Aug 1]. Available from: http://kostat.go.kr/portal/eng/pressReleases/8/1/index.board.

2. Binstock RH. Anti-aging medicine and research: a realm of conflict and profound societal implications. J Gerontol A Biol Sci Med Sci 
2004;59:B523-33.

3. Speakman JR, Mitchell SE. Caloric restriction. Mol Aspects Med 2011;32:159-221.

4. Masoro EJ. Overview of caloric restriction and ageing. Mech Ageing Dev 2005; 126:913-22.

5. McCay CM, Crowell MF, Maynard LA. The effect of retarded growth upon the length of life span and upon the ultimate body size: one figure. J Nutr 1935;10:63-79.

6. Longo VD, Mattson MP. Fasting: molecular mechanisms and clinical applications. Cell Metab 2014;19:181-92.

7. Mattison JA, Roth GS, Beasley TM, Tilmont EM, Handy AM, Herbert $\mathrm{RL}$, et al. Impact of caloric restriction on health and survival in rhesus monkeys from the NIA study. Nature 2012;489:318-21.

8. Al-Regaiey KA. The effects of calorie restriction on aging: a brief review. Eur Rev Med Pharmacol Sci 2016;20:2468-73.

9. Walford RL, Harris SB, Gunion MW. The calorically restricted low-fat nutrient-dense diet in Biosphere 2 significantly lowers blood glucose, total leukocyte count, cholesterol, and blood pressure in humans. Proc Natl Acad Sci U S A 1992;89:11533-7.

10. Canto C, Auwerx J. Calorie restriction: is AMPK a key sensor and effector? Physiology (Bethesda) 2011;26:214-24.

11. Imai SI, Guarente L. It takes two to tango: $\mathrm{NAD}(+)$ and sirtuins in aging/longevity control. NPJ Aging Mech Dis 2016;2:16017.

12. Mitchell SE, Delville C, Konstantopedos P, Hurst J, Derous D, Green C, et al. The effects of graded levels of calorie restriction: II. Impact of short term calorie and protein restriction on circulating hormone levels, glucose homeostasis and oxidative stress in male C57BL/6 mice. Oncotarget 2015;6:23213-37.

13. Yang F, Chu X, Yin M, Liu X, Yuan H, Niu Y, et al. mTOR and autophagy in normal brain aging and caloric restriction ameliorating age-related cognition deficits. Behav Brain Res 2014;264:82-90.

14. Saraswat K, Rizvi SI. Novel strategies for anti-aging drug discovery. Expert Opin Drug Discov 2017;12:955-66.

15. Ingram DK, Roth GS. Calorie restriction mimetics: can you have your cake and eat it, too? Ageing Res Rev 2015;20:46-62.

16. Ruderman N, Prentki M. AMP kinase and malonyl-CoA: targets for therapy of the metabolic syndrome. Nat Rev Drug Discov 2004;3:34051.

17. Rena G, Pearson ER, Sakamoto K. Molecular mechanism of action of metformin: old or new insights? Diabetologia 2013;56:1898-906.

18. Bannister CA, Holden SE, Jenkins-Jones S, Morgan CL, Halcox JP, Schernthaner $\mathrm{G}$, et al. Can people with type 2 diabetes live longer than those without?: a comparison of mortality in people initiated with metformin or sulphonylurea monotherapy and matched, non-diabetic controls. Diabetes Obes Metab 2014;16:1165-73.

19. UK Prospective Diabetes Study (UKPDS) Group. Effect of intensive blood-glucose control with metformin on complications in overweight patients with type 2 diabetes (UKPDS 34). Lancet 1998;352:854-65.

20. Wu JW, Boudreau DM, Park Y, Simonds NI, Freedman AN. Commonly used diabetes and cardiovascular medications and cancer recurrence and cancer-specific mortality: a review of the literature. Expert Opin Drug Saf 2014;13:1071-99.

21. Ng TP, Feng L, Yap KB, Lee TS, Tan CH, Winblad B. Long-term metformin usage and cognitive function among older adults with diabetes. $\mathrm{J}$ Alzheimers Dis 2014;41:61-8.
22. Bartke A. The somatotropic axis and aging: mechanisms and persistent questions about practical implications. Exp Gerontol 2009;44:3724 .

23. Junnila RK, List EO, Berryman DE, Murrey JW, Kopchick JJ. The GH/ IGF-1 axis in ageing and longevity. Nat Rev Endocrinol 2013;9:366-76.

24. Trainer PJ, Drake WM, Katznelson L, Freda PU, Herman-Bonert V, van der Lely AJ, et al. Treatment of acromegaly with the growth hormonereceptor antagonist pegvisomant. N Engl J Med 2000;342:1171-7.

25. Caron A, Richard D, Laplante M. The roles of mTOR complexes in lipid metabolism. Annu Rev Nutr 2015;35:321-48.

26. Josse L, Xie J, Proud CG, Smales CM. mTORC1 signalling and eIF4E/4E-BP1 translation initiation factor stoichiometry influence recombinant protein productivity from GS-CHOK1 cells. Biochem J 2016;473:4651-64.

27. Johnson SC, Rabinovitch PS, Kaeberlein M. mTOR is a key modulator of ageing and age-related disease. Nature 2013;493:338-45.

28. Arriola Apelo SI, Lamming DW. Rapamycin: an InhibiTOR of aging emerges from the soil of Easter Island. J Gerontol A Biol Sci Med Sci 2016;71:841-9.

29. Soefje SA, Karnad A, Brenner AJ. Common toxicities of mammalian target of rapamycin inhibitors. Target Oncol 2011;6:125-9.

30. Satoh A, Brace CS, Rensing N, Cliften P, Wozniak DF, Herzog ED, et al. Sirtl extends life span and delays aging in mice through the regulation of Nk2 homeobox 1 in the DMH and LH. Cell Metab 2013;18:416-30.

31. Wood JG, Rogina B, Lavu S, Howitz K, Helfand SL, Tatar M, et al. Sirtuin activators mimic caloric restriction and delay ageing in metazoans. Nature 2004;430:686-9.

32. Morselli E, Maiuri MC, Markaki M, Megalou E, Pasparaki A, Palikaras $\mathrm{K}$, et al. Caloric restriction and resveratrol promote longevity through the Sirtuin-1-dependent induction of autophagy. Cell Death Dis 2010;1:e10.

33. Chung S, Yao H, Caito S, Hwang JW, Arunachalam G, Rahman I. Regulation of SIRT1 in cellular functions: role of polyphenols. Arch Biochem Biophys 2010;501:79-90.

34. Howitz KT, Bitterman KJ, Cohen HY, Lamming DW, Lavu S, Wood JG, et al. Small molecule activators of sirtuins extend Saccharomyces cerevisiae lifespan. Nature 2003;425:191-6.

35. Baur JA, Pearson KJ, Price NL, Jamieson HA, Lerin C, Kalra A, et al. Resveratrol improves health and survival of mice on a high-calorie diet. Nature 2006;444:337-42.

36. Pearson KJ, Baur JA, Lewis KN, Peshkin L, Price NL, Labinskyy N, et al. Resveratrol delays age-related deterioration and mimics transcriptional aspects of dietary restriction without extending life span. Cell Metab 2008;8:157-68.

37. Yang DL, Zhang HG, Xu YL, Gao YH, Yang XJ, Hao XQ, et al. Resveratrol inhibits right ventricular hypertrophy induced by monocrotaline in rats. Clin Exp Pharmacol Physiol 2010;37:150-5.

38. Wu Z, Xu Q, Zhang L, Kong D, Ma R, Wang L. Protective effect of resveratrol against kainate-induced temporal lobe epilepsy in rats. Neurochem Res 2009;34:1393-400.

39. Khan MM, Ahmad A, Ishrat T, Khan MB, Hoda MN, Khuwaja G, et al. Resveratrol attenuates 6-hydroxydopamine-induced oxidative damage and dopamine depletion in rat model of Parkinson's disease. Brain Res 2010;1328:139-51.

40. Karuppagounder SS, Pinto JT, Xu H, Chen HL, Beal MF, Gibson GE. 
Dietary supplementation with resveratrol reduces plaque pathology in a transgenic model of Alzheimer's disease. Neurochem Int 2009;54: 111-8.

41. Witte AV, Kerti L, Margulies DS, Floel A. Effects of resveratrol on memory performance, hippocampal functional connectivity, and glucose metabolism in healthy older adults. J Neurosci 2014;34:7862-70.

42. Bhatt JK, Thomas S, Nanjan MJ. Resveratrol supplementation improves glycemic control in type 2 diabetes mellitus. Nutr Res 2012;32: 537-41.

43. Zouboulis CC, Makrantonaki E. Hormonal therapy of intrinsic aging. Rejuvenation Res 2012;15:302-12.

44. Rossouw JE, Anderson GL, Prentice RL, LaCroix AZ, Kooperberg C, Stefanick ML, et al. Risks and benefits of estrogen plus progestin in healthy postmenopausal women: principal results from the Women's Health Initiative randomized controlled trial. JAMA 2002;288:321-33.

45. Samaras N, Papadopoulou MA, Samaras D, Ongaro F. Off-label use of hormones as an antiaging strategy: a review. Clin Interv Aging 2014;9:1175-86.

46. Samaras N, Samaras D, Lang PO, Forster A, Pichard C, Frangos E, et al. A view of geriatrics through hormones: what is the relation between andropause and well-known geriatric syndromes? Maturitas 2013;74: 213-9.

47. Sim MY, Kim SH, Kim KM. Seasonal variations and correlations between vitamin D and total testosterone levels. Korean J Fam Med 2017;38:270-5.

48. Sattler FR, Castaneda-Sceppa C, Binder EF, Schroeder ET, Wang Y, Bhasin S, et al. Testosterone and growth hormone improve body composition and muscle performance in older men. J Clin Endocrinol Metab 2009;94:1991-2001.

49. Bain J. Andropause: testosterone replacement therapy for aging men. Can Fam Physician 2001;47:91-7.

50. Emmelot-Vonk MH, Verhaar HJ, Nakhai Pour HR, Aleman A, Lock TM, Bosch JL, et al. Effect of testosterone supplementation on functional mobility, cognition, and other parameters in older men: a randomized controlled trial. JAMA 2008;299:39-52.

51. Kenny AM, Kleppinger A, Annis K, Rathier M, Browner B, Judge JO, et al. Effects of transdermal testosterone on bone and muscle in older men with low bioavailable testosterone levels, low bone mass, and physical frailty. J Am Geriatr Soc 2010;58:1134-43.

52. Noble RL. The development of prostatic adenocarcinoma in $\mathrm{Nb}$ rats following prolonged sex hormone administration. Cancer Res 1977;37:1929-33.

53. Pierorazio PM, Ferrucci L, Kettermann A, Longo DL, Metter EJ, Carter HB. Serum testosterone is associated with aggressive prostate cancer in older men: results from the Baltimore Longitudinal Study of Aging. BJU Int 2010;105:824-9.

54. Travis RC, Key TJ, Allen NE, Appleby PN, Roddam AW, Rinaldi S, et al. Serum androgens and prostate cancer among 643 cases and 643 controls in the European Prospective Investigation into Cancer and Nutrition. Int J Cancer 2007;121:1331-8.

55. Genazzani AD, Lanzoni C, Genazzani AR. Might DHEA be considered a beneficial replacement therapy in the elderly? Drugs Aging 2007;24:173-85.

56. Davis SR, Panjari M, Stanczyk FZ. Clinical review: DHEA replacement for postmenopausal women. J Clin Endocrinol Metab 2011;96:1642-
53.

57. Valenti G, Denti L, Maggio M, Ceda G, Volpato S, Bandinelli S, et al. Effect of DHEAS on skeletal muscle over the life span: the InCHIANTI study. J Gerontol A Biol Sci Med Sci 2004;59:466-72.

58. Ravaglia G, Forti P, Maioli F, Boschi F, Cicognani A, Bernardi M, et al. Determinants of functional status in healthy Italian nonagenarians and centenarians: a comprehensive functional assessment by the instruments of geriatric practice. J Am Geriatr Soc 1997;45:1196-202.

59. Nawata H, Tanaka S, Tanaka S, Takayanagi R, Sakai Y, Yanase T, et al. Aromatase in bone cell: association with osteoporosis in postmenopausal women. J Steroid Biochem Mol Biol 1995;53:165-74.

60. Clarke BL, Ebeling PR, Jones JD, Wahner HW, O’Fallon WM, Riggs BL, et al. Predictors of bone mineral density in aging healthy men varies by skeletal site. Calcif Tissue Int 2002;70:137-45.

61. Barrett-Connor E, Goodman-Gruen D, Patay B. Endogenous sex hormones and cognitive function in older men. J Clin Endocrinol Metab 1999;84:3681-5.

62. Michael A, Jenaway A, Paykel ES, Herbert J. Altered salivary dehydroepiandrosterone levels in major depression in adults. Biol Psychiatry 2000;48:989-95.

63. Shufelt C, Bretsky P, Almeida CM, Johnson BD, Shaw LJ, Azziz R, et al. DHEA-S levels and cardiovascular disease mortality in postmenopausal women: results from the National Institutes of Health--National Heart, Lung, and Blood Institute (NHLBI)-sponsored Women's Ischemia Syndrome Evaluation (WISE). J Clin Endocrinol Metab 2010;95: 4985-92.

64. Legrain S, Massien C, Lahlou N, Roger M, Debuire B, Diquet B, et al. Dehydroepiandrosterone replacement administration: pharmacokinetic and pharmacodynamic studies in healthy elderly subjects. J Clin Endocrinol Metab 2000;85:3208-17.

65. Traish AM, Kang HP, Saad F, Guay AT. Dehydroepiandrosterone (DHEA): a precursor steroid or an active hormone in human physiology. J Sex Med 2011;8:2960-82.

66. Nair KS, Rizza RA, O’Brien P, Dhatariya K, Short KR, Nehra A, et al. DHEA in elderly women and DHEA or testosterone in elderly men. $\mathrm{N}$ Engl J Med 2006;355:1647-59.

67. Vaiserman AM, Koliada AK, Marotta F. Gut microbiota: a player in aging and a target for anti-aging intervention. Ageing Res Rev 2017;35:36-45.

68. Konturek PC, Haziri D, Brzozowski T, Hess T, Heyman S, Kwiecien S, et al. Emerging role of fecal microbiota therapy in the treatment of gastrointestinal and extra-gastrointestinal diseases. J Physiol Pharmacol 2015;66:483-91.

69. Biagi E, Franceschi C, Rampelli S, Severgnini M, Ostan R, Turroni S, et al. Gut microbiota and extreme longevity. Curr Biol 2016;26:1480-5.

70. Rampelli S, Candela M, Turroni S, Biagi E, Collino S, Franceschi C, et al. Functional metagenomic profiling of intestinal microbiome in extreme ageing. Aging (Albany NY) 2013;5:902-12.

71. Perez Martinez G, Bauerl C, Collado MC. Understanding gut microbiota in elderly's health will enable intervention through probiotics. Benef Microbes 2014;5:235-46.

72. Rondanelli M, Giacosa A, Faliva MA, Perna S, Allieri F, Castellazzi AM. Review on microbiota and effectiveness of probiotics use in older. World J Clin Cases 2015;3:156-62.

73. Eloe-Fadrosh EA, Brady A, Crabtree J, Drabek EF, Ma B, Mahurkar A, 
et al. Functional dynamics of the gut microbiome in elderly people during probiotic consumption. MBio 2015;6:e0231-15.

74. Young VB, Hayden MK. Environmental management in the gut: fecal transplantation to restore the intestinal ecosystem. Infect Dis (Lond) 2016;48:593-5.

75. Rao K, Safdar N. Fecal microbiota transplantation for the treatment of Clostridium difficile infection. J Hosp Med 2016;11:56-61.

76. Choi HH, Cho YS. Fecal microbiota transplantation: current applications, effectiveness, and future perspectives. Clin Endosc 2016;49:25765.

77. Wang TJ, Pencina MJ, Booth SL, Jacques PF, Ingelsson E, Lanier K, et al. Vitamin D deficiency and risk of cardiovascular disease. Circulation 2008;117:503-11.

78. Balion C, Griffith LE, Strifler L, Henderson M, Patterson C, Heckman G, et al. Vitamin D, cognition, and dementia: a systematic review and meta-analysis. Neurology 2012;79:1397-405.

79. Janssen HC, Samson MM, Verhaar HJ. Vitamin D deficiency, muscle function, and falls in elderly people. Am J Clin Nutr 2002;75:611-5.
80. Douglas AS, Dunnigan MG, Allan TM, Rawles JM. Seasonal variation in coronary heart disease in Scotland. J Epidemiol Community Health 1995;49:575-82.

81. Rostand SG. Ultraviolet light may contribute to geographic and racial blood pressure differences. Hypertension 1997;30(2 Pt 1):150-6.

82. Kim MH, Kim YS, Oh HJ, Kwon YR, Kim HW. The association between 10-year atherosclerotic cardiovascular diseases risk score calculated using 2013 American College of Cardiology/American Heart Association guidelines and serum 25-hydroxyvitamin $\mathrm{D}$ level among aged 4079 years in Korea: the sixth Korea National Health and Nutrition Examination Surveys. Korean J Fam Med 2018;39:174-9.

83. Deeb KK, Trump DL, Johnson CS. Vitamin D signalling pathways in cancer: potential for anticancer therapeutics. Nat Rev Cancer 2007;7:684-700.

84. Pludowski P, Holick MF, Grant WB, Konstantynowicz J, Mascarenhas MR, Haq A, et al. Vitamin D supplementation guidelines. J Steroid Biochem Mol Biol 2018;175:125-35. 